\title{
Investigating lead removal at trace concentrations from water by inactive yeast cells
}

Patritsia M. Stathatou ${ }^{1}{ }^{\dagger}$, Christos E. Athanasiou ${ }^{1,2 * \dagger}$, Marios Tsezos ${ }^{3}$, John W. Goss ${ }^{4}$, Camron Blackburn $^{1}$, Filippos Tourlomousis ${ }^{1}$, Andreas Mershin ${ }^{1}$, Brian W. Sheldon ${ }^{2}$, Nitin P. Padture ${ }^{2}$, Eric M. Darling ${ }^{2,5,6,7}$, Huajian $\mathrm{Gao}^{2,8}$, Neil Gershenfeld ${ }^{1 *}$

${ }^{1}$ Center for Bits and Atoms, Massachusetts Institute of Technology; Cambridge, MA, USA.

${ }^{2}$ School of Engineering, Brown University; Providence, RI, USA.

${ }^{3}$ School of Mining Engineering and Metallurgy, National Technical University of Athens; Athens, Greece.

${ }^{4}$ Department of Biological Sciences, Wellesley College; Wellesley, MA, USA.

${ }^{5}$ Center for Biomedical Engineering, Brown University; Providence, RI, USA.

${ }^{6}$ Department of Pathology and Laboratory Medicine, Brown University; Providence, RI, USA.

${ }^{7}$ Department of Orthopaedics, Brown University; Providence, RI, USA.

${ }^{8}$ School of Mechanical and Aerospace Engineering, College of Engineering, Nanyang Technological University; Singapore, Singapore.

*Corresponding author. Emails: pstath@mit.edu; christos_edouardos_athanasiou@brown.edu; neil.gershenfeld@cba.mit.edu

$\dagger$ These authors contributed equally to this work.

Abstract: Traces of heavy metals found in water resources, due to mining activities and e-waste discharge, pose a global threat. Conventional treatment processes fail to remove toxic heavy metals, such as lead, from drinking water in a resource-efficient manner when their initial concentrations are low. Here, we show that by using the yeast Saccharomyces cerevisiae we can effectively remove trace lead from water via a rapid mass transfer process, achieving an uptake of up to $12 \mathrm{mg}$ lead per gram of biomass in solutions with initial lead concentrations below 1 part per million. We found that the yeast cell wall plays a crucial role in this process, with its mannoproteins and $\beta$-glucans being the key potential lead adsorbents. Furthermore, we discovered that biosorption is linked to a significant increase in cell wall stiffness. These findings open new opportunities for using environmentally friendly and abundant biomaterials for advanced water treatment targeting emerging contaminants.

One-Sentence Summary: Removing toxic heavy metals from water at challenging trace levels in an environmentally friendly, resource-efficient manner. 
Heavy metals are highly water-soluble and non-biodegradable, tending to persist indefinitely when released into water bodies. Electronic waste (e-waste) discharge and mining are the most dominant anthropogenic activities responsible for heavy metal contamination of water resources(1). Acid mine drainage (AMD), i.e., leakage of highly acidic water rich in metals, is a global environmental threat(2). In the United States (US) alone, AMD is the main source of water pollution, impacting currently over $20,000 \mathrm{~km}$ of streams(3), deriving from the 13,000 active and the 500,000 abandoned mines(4), which continue generating AMD for centuries after their closure(5). In addition, around 50 million tons of e-waste was globally produced in 2018, expected to reach 120 million tons per year by 2050 . Over $80 \%$ of this e-waste either ends up in landfills or is being recycled under poorly regulated conditions, using primitive and pollutive methods, hence, seriously contaminating water resources $(6)$.

Lead $(\mathrm{Pb})$ is one of the most widely used heavy metals; its production increased by about $20 \%$ during the last decade, reaching around 11.7 million tons globally in 2020(7). $\mathrm{Pb}$ is highly toxic, even at trace concentrations, with deleterious effects on organs and tissues of the human body $(8)$. It can enter drinking water either due to inadequate water treatment, or due to chemical reactions with $\mathrm{Pb}$-containing components of water distribution systems $(9,10)$. After numerous incidents of $\mathrm{Pb}$ contamination $(9,11)$, with most recent the water crisis in the city of Flint, Michigan, USA in 2014 , limits of $\mathrm{Pb}$ in drinking water are becoming more stringent: in 2018, the European Commission proposed reducing $\mathrm{Pb}$ limits to 5 parts per billion (ppb)(12), while in 2020, the US Environmental Protection Agency determined that no level of $\mathrm{Pb}$ in drinking water is safe(13).

Conventional water treatment methods either fail to completely remove trace $\mathrm{Pb}$ amounts or result in significant financial and environmental costs to do so(14-16). Biosorption, a mass transfer process by which heavy metal ions bind onto inactive biological materials by physicochemical interactions, is a competitive alternative to conventional processes, as abundant biomass sources can be effective, practical, and sustainable adsorbents(17). Although biosorption of heavy metals has been studied at the parts per million (ppm) contaminants scale, there is a significant research gap at the challenging trace initial concentrations of ppb and below.

In this study, the unexplored $\mathrm{Pb}$ biosorption mechanisms at the ppb scale are investigated using inactive yeast biomass as the biosorbent. A strain of the common yeast, Saccharomyces cerevisiae (S. cerevisiae), was selected, as it is a biodegradable adsorbent, widely used in various industrial settings $(15,18)$, that effectively remove $\mathrm{Pb}$ at $\mathrm{ppm}$ initial concentrations $(19)$. The yeast cells were harvested at the peak of their exponential growth phase (Fig. 1A), for optimal biosorptive capacity(19). The harvested cells were washed to remove culture medium residues and metabolites (Fig. 1B), before being lyophilized (freeze-dried) and converted to powder (Fig. 1C). Kinetic and equilibrium experiments were conducted by adding this yeast powder biomaterial to ultrapure water spiked with lead(II) nitrate $\left(\mathrm{Pb}\left(\mathrm{NO}_{3}\right)_{2}\right)$. After the required contact time, liquid and solid phases were separated and analyzed to measure residual $\mathrm{Pb}$ concentrations and identify potential biomass sites responsible for Pb uptake (Fig. 1D). Overall, this work showcases the use of an effective trace heavy-metal removal biomaterial, made from an environmentally friendly, inexpensive, benign to human health, and easy-to-mass-produce microorganism. 

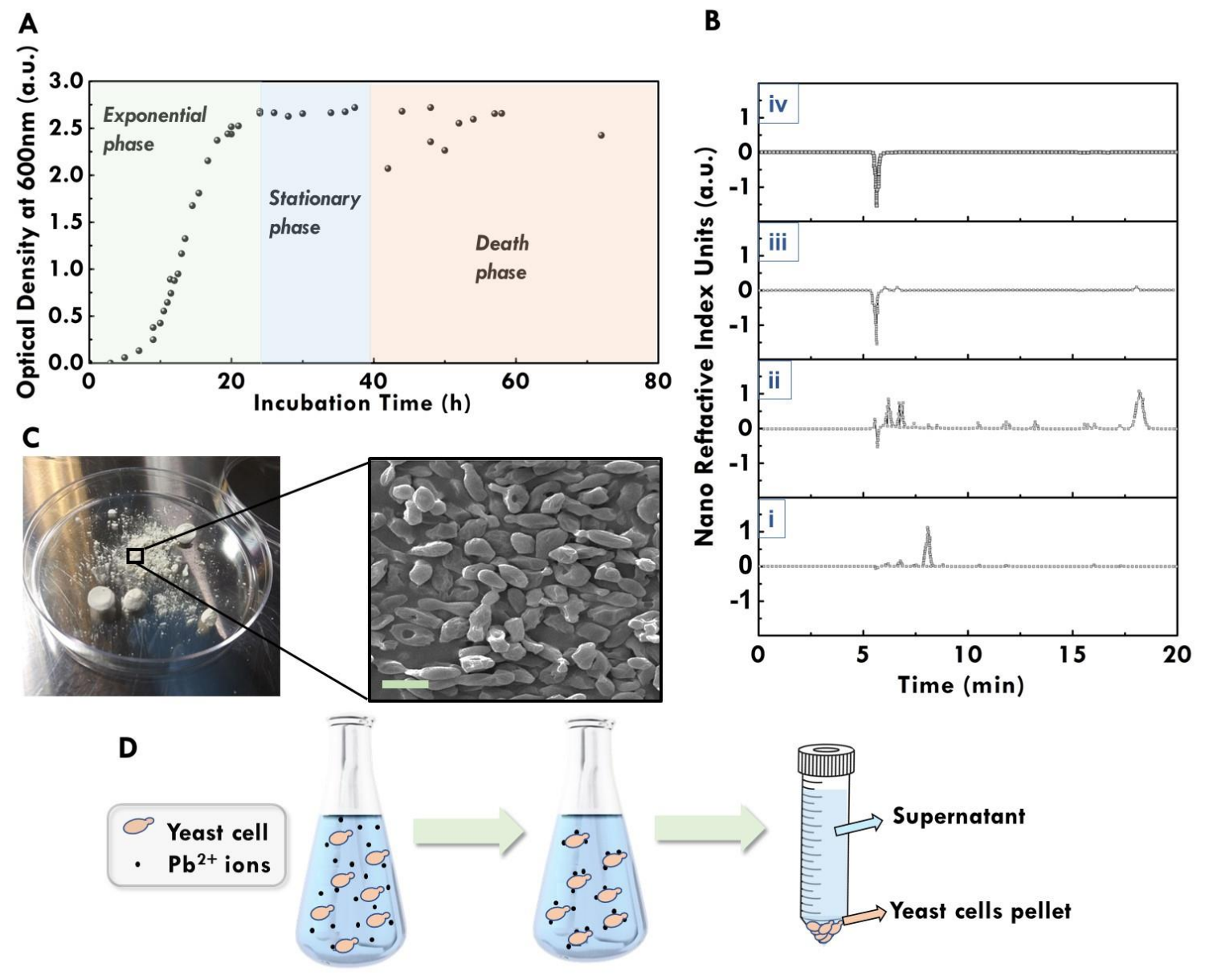

Fig. 1. Overview of experimental procedures. (A) Measured growth curve of S. cerevisiae yeast cells (absorbance accuracy is approximately $1.75 \%$ of reported values). (B) Highperformance liquid chromatography (HPLC) analysis results, performed to identify the number of washes with ultrapure water required to remove medium residues and metabolites from harvested yeast cells before being used in biosorption experiments: i) pure culture medium showed a peak at 8 mins representing glucose; ii) in the supernatant of the harvested liquid culture, glucose was not present but ethanol was produced (peak at 18 mins); iii) in the supernatant after the first wash of yeast cells with ultrapure water there were almost no peaks representing the presence of sugars or organic acids in the solution; iv) in the supernatant after the second wash of yeast cells with ultrapure water there were no peaks at all. Therefore, it was decided to wash the harvested cells twice to ensure absence of organic compounds that might affect further experiments. (C) Yeast powder after lyophilization and scanning electron microscope (SEM) imaging of freeze-dried yeast cells (scale bar: $5 \mu \mathrm{m}$ ). (D) Main steps of kinetic and equilibrium experiments involving the addition of freeze-dried yeast cells in $\mathrm{Pb}$ containing aqueous solutions, the adsorption of $\mathrm{Pb}$ ions, and the separation of biomass and supernatant after the required contact time via centrifugation for further analyses. 


\section{Results}

Effect of solution pH on Pb speciation and uptake. Solution $\mathrm{pH}$ is a key parameter for biosorption, as it affects the chemistry and speciation of both the metal-uptaking functional groups in the biomass, and of the hydrolyzed $\mathrm{Pb}$ ionic forms. $\mathrm{Pb}$ speciation in the solution is also affected by the $\mathrm{Pb}$ concentration at any given $\mathrm{pH}$ and oxidation state $(17,20)$. To quantify the resulting $\mathrm{Pb}$ speciation after the hydrolysis of $\mathrm{Pb}\left(\mathrm{NO}_{3}\right)_{2}$ in a wide $\mathrm{pH}$ range (3-13), at $25^{\circ} \mathrm{C}$, and at a given initial concentration $\left(C_{0}\right)$ of $1 \mu \mathrm{M} \mathrm{Pb}\left(\mathrm{NO}_{3}\right)_{2}$, the Eawag ChemEQL v3.2 software(21) was used. $\mathrm{Pb}^{2+}$ is the dominant species until $\mathrm{pH}$ reaches 5.8, where lead hydroxides (e.g., $\mathrm{PbOH}^{+}$) are beginning to form (Fig. 2A).

Solution $\mathrm{pH}$ increases with the addition of biomass and plateaus for biomass values greater than $100 \mathrm{mg}$ (Fig. 2B). Therefore, to assess the effect of solution $\mathrm{pH}$ on the biomass $\mathrm{Pb}^{2+}$ uptake capacity ( $q$, in $\mu \mathrm{g}$ of $\mathrm{Pb}^{2+}$ by $\mathrm{g}$ of biomass), the initial $\mathrm{pH}$ of the aqueous solution (before biomass addition) was adjusted to $\mathrm{pH}$ values within the range of 3-7, and then $5 \mathrm{mg}$ of yeast biomass were added to moderate the anticipated $\mathrm{pH}$ increase due to biomass addition. $\mathrm{Pb}^{2+}$ concentrations and $\mathrm{pH}$ values were measured both before biomass addition and after $\mathrm{Pb}^{2+}$ biosorption (contact time of $24 \mathrm{~h}$ ). The biomass $\mathrm{Pb}^{2+}$ uptake capacity increased significantly as the initial solution $\mathrm{pH}$ was increased from 3 to 5 (Fig. 2C). For $\mathrm{pH} \geq 6.0$ the measured initial $\mathrm{Pb}^{2+}$ concentration was significantly lower than the known amount added to the solutions, indicating loss of soluble $\mathrm{Pb}$ analytes due to precipitation. This is validated by the formation of lead hydroxides after $\mathrm{pH} 5.8$ (Fig. 2A). The increase of solution $\mathrm{pH}$ by biomass addition, as well as the increase of $q$ with increasing $\mathrm{pH}$ values could be attributed to a potential protonation of the functional groups of yeast biomass at $\mathrm{pH}$ values below the $\mathrm{pH}$ point zero, i.e., the $\mathrm{pH}$ at which the overall biomass surface charge is zero. At $\mathrm{pH}$ values below the $\mathrm{pH}$ point zero, the biomaterial may exhibit an overall positive charge, thus attracting negatively charged species and not adsorbing $\mathrm{Pb}^{2+}$ cations resulting in lower $q$ values, while at higher $\mathrm{pH}$ values the biomass surface could acquire negative charges leading to increased $\mathrm{Pb}^{2+}$ uptake. However, such an approach assumes a rather simplistic electrostatic attraction driving mechanism, which has been shown not to be the only case in biosorption(17).

Based on these results, $\mathrm{pH} 5$ was proven to be the most suitable for Pb biosorption, where soluble $\mathrm{Pb}^{2+}$ is the most dominant species in the solution and $q$ is maximized. All experiments described in the following sections were performed by adding $5 \mathrm{mg}$ of yeast biomass (unless otherwise specified) in aqueous solutions, after adjusting their initial $\mathrm{pH}$ to 5 at $25^{\circ} \mathrm{C}$, agitated at $200 \mathrm{rpm}$.

Adsorption kinetics \& growth analysis of lyophilized yeast. Kinetic experiments were conducted to determine the change in $\mathrm{Pb}^{2+}$ concentration in the liquid phase as a function of contact time and identify the contact time required to attain equilibrium. Lyophilized yeast cells were added in aqueous solutions with $C_{0}$ of $100 \mathrm{ppb} \mathrm{Pb}^{2+}$ and were incubated for 24 hours. Samples were taken at specific time intervals (i.e., $0 \mathrm{~min}, 5 \mathrm{~min}, 15 \mathrm{~min}, 30 \mathrm{~min}, 1 \mathrm{~h}, 2 \mathrm{~h}, 4 \mathrm{~h}, 8 \mathrm{~h}, 24 \mathrm{~h}$ ) and analyzed using inductively coupled plasma mass spectrometry (ICP-MS). As observed, biosorption is a rapid process, with equilibrium being reached within the first five minutes of contact (Fig. 2D). Kinetics data fit accurately with the pseudo-first-order model(22), $\left(\mathrm{R}^{2}: 0.99\right)$, with the pseudo-first-order rate constant $\left(k_{l}\right)$ equal to $111.98 \mathrm{~h}^{-1}$.

In parallel the freeze-dried $S$. cerevisiae cells were incubated for $24 \mathrm{~h}$ under conditions identical to the kinetic experiments and observed by phase-contrast microscopy, while acquiring optical 
density (OD) measurements, to validate that the cells remain inactive during biosorption. Indeed, after $24 \mathrm{~h}$ there was neither cell growth nor cell division observed (Fig. 2D); time-lapse video and further information confirming these results are included in the Supplementary Materials of this work.

Adsorption isotherm. Aqueous solutions with different initial $\mathrm{Pb}^{2+}$ concentrations $\left(C_{0}: 20,40\right.$, $100,200,300,500,700$, and 1,000 ppb) were incubated for $1 \mathrm{~h}$. The equilibrium $\mathrm{Pb}^{2+}$ concentrations $(\mathrm{Ceq})$ were measured after biosorption, and the $\mathrm{Pb}^{2+}$ uptake capacity of yeast biomass at equilibrium $\left(q_{e}\right)$ was calculated (using Equitation 1 of Supplementary Materials) to develop the adsorption isotherm (Fig. 2E). The maximum $q_{e}$ measured is equal to $12 \mathrm{mg} / \mathrm{g}$, for aqueous solutions with $C_{0}$ of $1,000 \mathrm{ppb} \mathrm{Pb}^{2+}$. The experimental data are accurately fitting with the Langmuir adsorption isotherm model $(23)\left(\mathrm{R}^{2}: 0.98\right)$, with the ratio of the adsorption and desorption rates $\left(K_{L}\right)$ equal to $1.5 \mathrm{~L} / \mathrm{mg}$, and the maximum estimated adsorption capacity $\left(q_{m}\right)$ equal to $21 \mathrm{mg} / \mathrm{g}$. However, this fit cannot provide any meaningful insight into the biosorption mechanism $(17,24)$.

$\mathrm{Pb}^{2+}$ percentage removal versus $\mathrm{Pb}^{2+} C_{0}$ was also measured (Fig. $2 \mathrm{~F}$ ). $\mathrm{Pb}^{2+}$ removal for $C_{0} 20 \mathrm{ppb}$ $\mathrm{Pb}^{2+}$ is approximately $25 \%$ and increases with the increase of $C_{0}$, reaching a maximum of $43 \%$ at $C_{0} 300 \mathrm{ppb} \mathrm{Pb}^{2+}$. After this point, $\mathrm{Pb}^{2+}$ removal decreases gradually with the decrease of $C_{0}$, indicating that the optimum uptake capacity of the yeast biomass quantity $(5 \mathrm{mg})$ is reached around $C_{0} 300 \mathrm{ppb} \mathrm{Pb}^{2+}$.

A
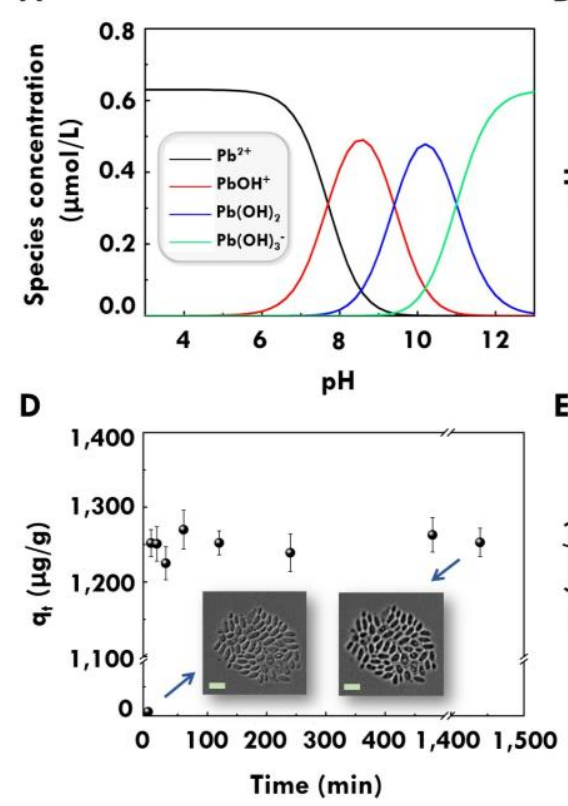

B

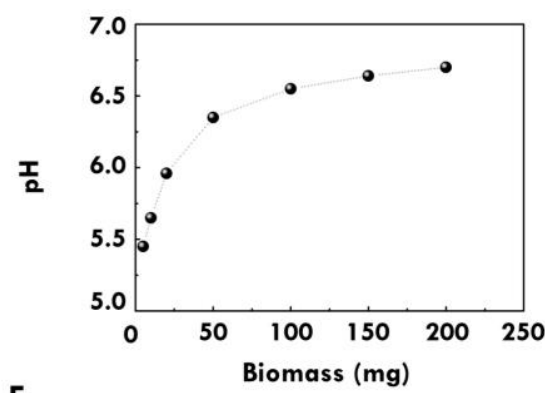

$\mathbf{E}$

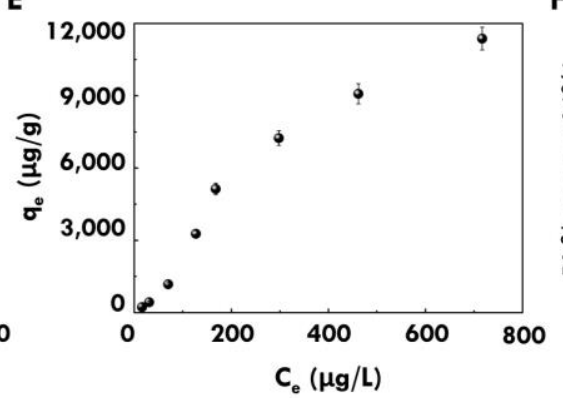

$\mathbf{F}$
C
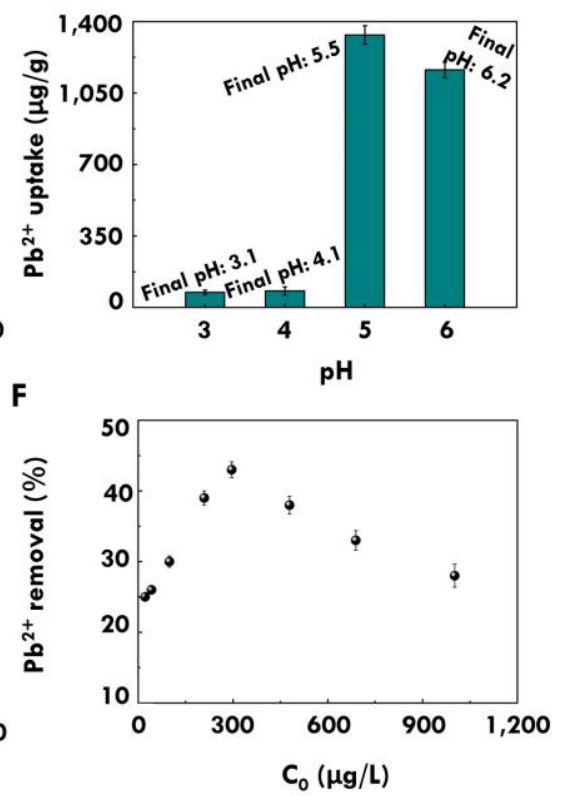

Fig. 2: Effect of solution pH on Pb speciation \& uptake, biosorption kinetics, and adsorption isotherm. (A) Distribution of $\mathrm{Pb}\left(\mathrm{NO}_{3}\right)_{2}$ hydrolysis products at $25^{\circ} \mathrm{C}$ and $1 \mu \mathrm{M}$ $\mathrm{Pb}\left(\mathrm{NO}_{3}\right)_{2}$. (B) Increase in solution $\mathrm{pH}$ due to yeast biomass addition; error: $\pm 0.06 \mathrm{pH}$ units. (C)

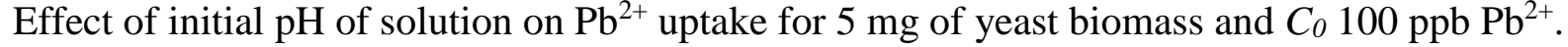
The final $\mathrm{pH}$ of solutions after biosorption is reported for each case; error: $\pm 0.06 \mathrm{pH}$ units. (D) Kinetic experiment of $5 \mathrm{mg}$ yeast biomass with $C_{0} 100 \mathrm{ppb} \mathrm{Pb}^{2+}$, indicating the rapid biosorption 
process; $q_{t}: \mathrm{Pb}^{2+}$ uptake capacity of yeast biomass at different time intervals ( $\mu \mathrm{g}$ of $\mathrm{Pb}^{2+}$ by $\mathrm{g}$ of biomass). Time course micrographs of lyophilized $S$. cerevisiae cells incubated in the same aqueous solution at $0 \mathrm{~h}$ and $24 \mathrm{~h}$ are shown in the inset, validating that there is no cell growth or division during the experiments (scale bar: $8 \mu \mathrm{m}$ ). (E) Adsorption isotherm at $25^{\circ} \mathrm{C}$, following the Langmuir adsorption isotherm model; $q_{e}: \mathrm{Pb}^{2+}$ uptake capacity of yeast biomass at equilibrium ( $\mu \mathrm{g}$ of $\mathrm{Pb}^{2+}$ by $\mathrm{g}$ of biomass). (F) $\mathrm{Pb}^{2+}$ percentage removal versus $\mathrm{Pb}^{2+} C_{0}$.

Yeast biomass imaging. Extracellular and intracellular imaging of yeast cells was performed to observe potential changes in their structure after biosorption, using SEM and transmission electron microscope (TEM) imaging, respectively. Yeast cells harvested from ultrapure water $\left(C_{0}: 0 \mathrm{ppb} \mathrm{Pb}^{2+}\right)$, served as control cells and were compared with yeast cells harvested from aqueous solutions of $C_{0} 100 \mathrm{ppb} \mathrm{Pb}^{2+}$. No morphological change was observed in the yeast cells after $\mathrm{Pb}^{2+}$ biosorption, with the structure and dimensions of the cell wall and cytoplasm remaining the same (Fig. 3A, B). Yeast cell walls were $\sim 180 \mathrm{~nm}$ thick, which is the typical cellwall thickness of the yeast strain used(25). However, yeast cell walls became more electrondense after $\mathrm{Pb}^{2+}$ biosorption, indicating the binding of $\mathrm{Pb}^{2+}$ ions on them, and in particular on the outer part of the cell wall (Fig. 3C, D).

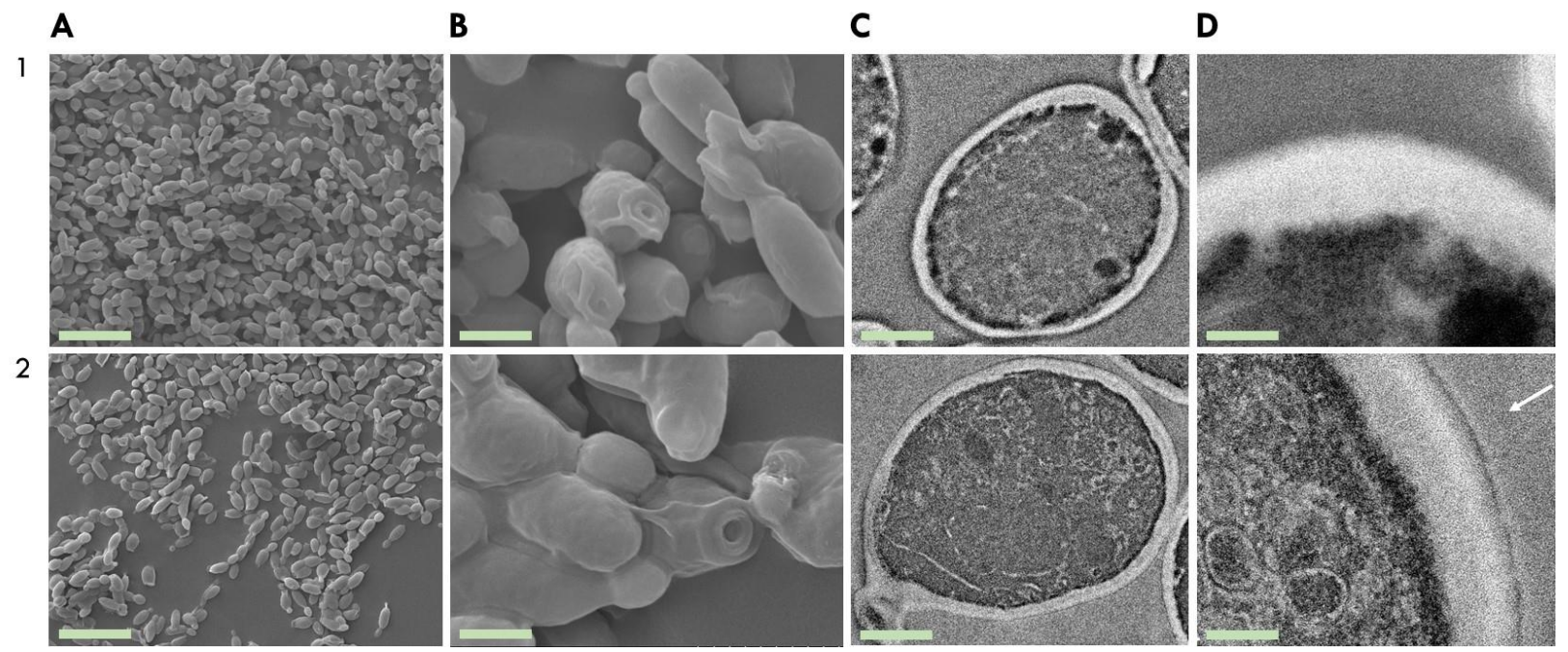

Fig. 3: SEM and TEM imaging of yeast cells. Rows are ordered as follows: control yeast cells $\left(C_{0}: 0 \mathrm{ppb}\right)(1)$, yeast cells after $\mathrm{Pb}^{2+}$ biosorption $\left(C_{0}: 100 \mathrm{ppb}\right)(2)$. (A) SEM images presenting an overview of yeast cells (scale bar: $10 \mu \mathrm{m}$ ). (B) Magnified SEM images showing individual yeast cells (scale bar: $2 \mu \mathrm{m}$ ). (C) TEM images of individual yeast cells (scale bar: $1 \mu \mathrm{m}$ ). (D) Magnified TEM images of yeast cell walls (scale bar: $200 \mathrm{~nm}$ ). The white arrow refers to the outer part of the cell wall, highlighting electron-dense $\mathrm{Pb}^{2+}$-binding areas.

Yeast biomass spectroscopy. Metal biosorption is thought to occur through interactions with functional groups native to the biomass cell wall(26). Attenuated-total-reflectance enhanced Fourier transformed infrared spectroscopy (ATR-FTIR) was performed to identify functional groups present in the yeast cell wall and detect changes in them after biosorption, indicating their involvement in $\mathrm{Pb}^{2+}$ adsorption. Freeze-dried control $\left(C_{0}: 0 \mathrm{ppb} \mathrm{Pb}^{2+}\right)$ and $\mathrm{Pb}^{2+}$-exposed yeast 
cells $\left(C_{0}\right.$ : 100 and 1,000 $\left.\mathrm{ppb} \mathrm{Pb}^{2+}\right)$ were analyzed using ATR-FTIR (Fig. 4A). Changes were observed after biosorption in peaks representing $\mathrm{C} \equiv \mathrm{N}$ and $\mathrm{C} \equiv \mathrm{C}$ stretches, while peak shifts were detected corresponding to $\mathrm{N}-\mathrm{H}$ in-plane bending from secondary protein amides, which overlaps with the $\mathrm{C}-\mathrm{N}$ and $\mathrm{NO}_{2}$ asymmetric stretching, to vibrational changes of the $\mathrm{C}-\mathrm{N}$ amide group, and to $\mathrm{C}-\mathrm{O}$ stretching in the esters and carboxylic acid groups. These changes indicate the contribution of amide and carboxylic acid groups to $\mathrm{Pb}^{2+}$ biosorption and the potential role of $\mathrm{N}$ in the yeast cell wall on $\mathrm{Pb}^{2+}$ binding.

In addition, the chemical composition of the yeast surface before $\left(C_{0}: 0 \mathrm{ppb} \mathrm{Pb}^{2+}\right)$ and after

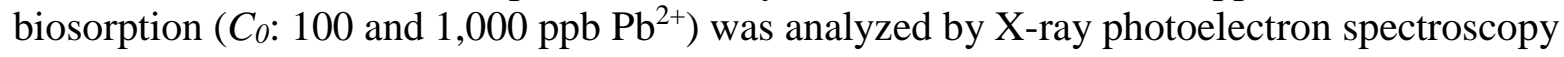
(XPS) to further explore potential changes in the functional groups of the yeast cell walls. The yeast surface is mainly composed of carbon $(\mathrm{C})$, oxygen $(\mathrm{O})$, and nitrogen $(\mathrm{N})(27,28)$.

Therefore, $\mathrm{C} 1 s, \mathrm{O} 1 s, \mathrm{~N} 1 s$ core levels spectra were recorded together with the $\mathrm{Pb} 4 f$. Significant changes among the control and the $\mathrm{Pb}^{2+}$-exposed yeast were only observed for the $\mathrm{C} 1 \mathrm{~s}$ spectrum, while changes in the $\mathrm{Pb}$ spectra could not be detected as the analyzed trace $\mathrm{Pb}^{2+}$ concentrations were below the detection limit of the instrument. Deconvolution of the $\mathrm{C} 1 s$ spectrum into Gaussian-shaped lines was performed to identify possible chemical bonds between $\mathrm{C}, \mathrm{O}$, and $\mathrm{N}$ (Fig. 4B). In all three samples, the $\mathrm{C} 1 s$ peaks are decomposed to peaks at $284.3 \mathrm{eV}$, $285.9 \mathrm{eV}, 287.5 \mathrm{eV}$, and $288.6 \mathrm{eV}$ representing $\mathrm{C}-\mathrm{C}\left(s p^{3} \mathrm{C}\right), \mathrm{C}-\mathrm{N}, \mathrm{O}-\mathrm{C}=\mathrm{O}$, and $\mathrm{C}=\mathrm{O}$ respectively. The magnitude and shape of all observed bonds have radically changed after $\mathrm{Pb}^{2+}$ biosorption, particularly for $\mathrm{C}-\mathrm{C}, \mathrm{C}-\mathrm{N}$, and $\mathrm{O}-\mathrm{C}=\mathrm{O}$ bonds. These changes indicate the contribution of carboxylic acid and amide groups on $\mathrm{Pb}^{2+}$ adsorption, which is consistent with the ATR-FTIR results.

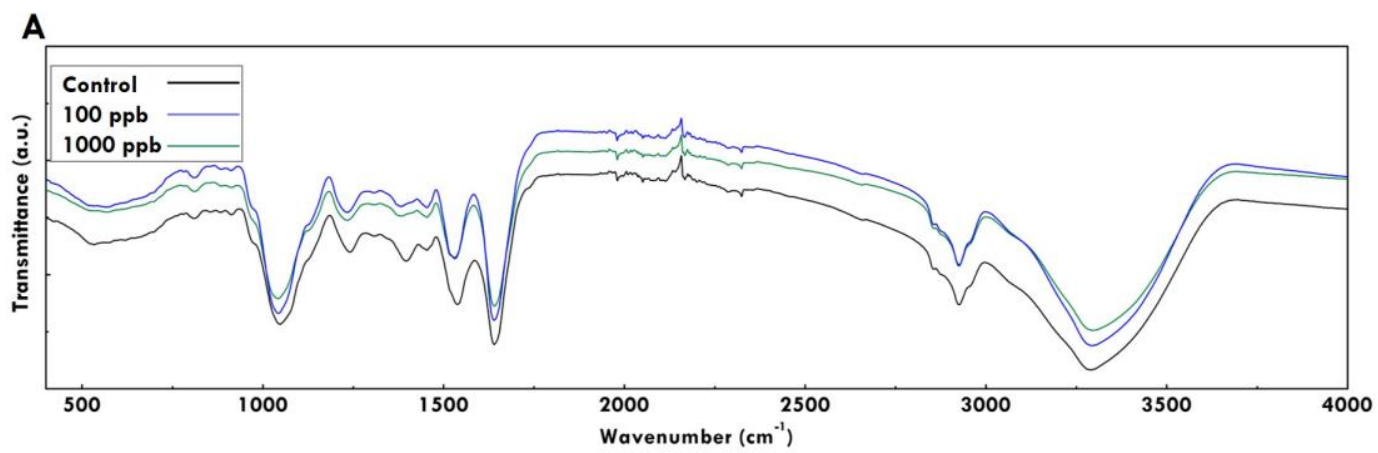

B
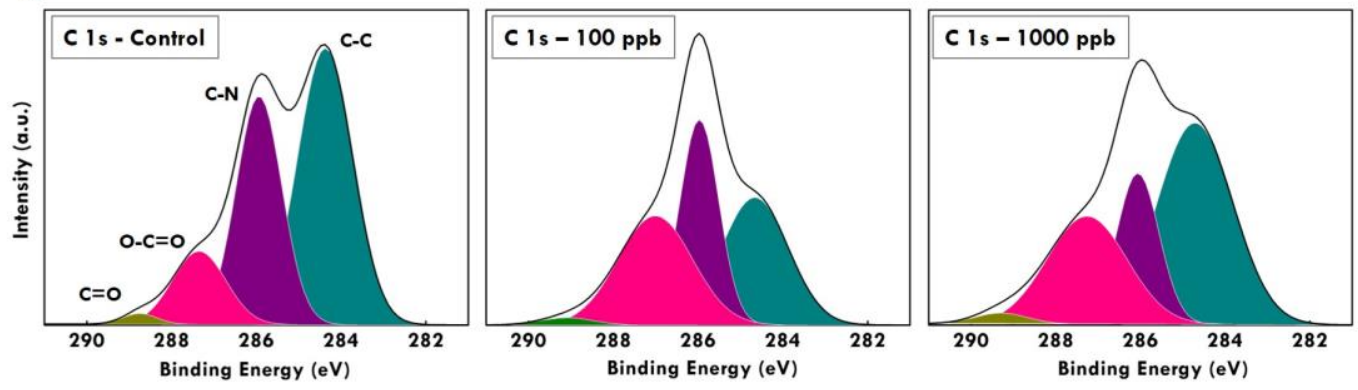

Fig. 4: ATR-FTIR and XPS characterization of yeast biomass. (A) Full ATR-FTIR spectrum of yeast cells. The black line represents control yeast cells $\left(C_{0}: 0 \mathrm{ppb} \mathrm{Pb}^{2+}\right)$; the blue and green lines represent yeast cells after biosorption with $C_{0} 100$ and $1,000 \mathrm{ppb} \mathrm{Pb}^{2+}$ respectively. (B) XPS analysis of yeast cells. From left to right: control cells, yeast cells after biosorption, $C_{0} 100$ 


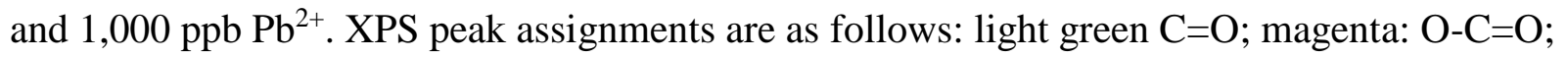
purple: C-N; dark green: C-C.

Chitin's contribution to $\boldsymbol{P b}^{2+}$ adsorption. The above analyses indicate that the cell wall of $S$. cerevisiae plays a vital role in $\mathrm{Pb}^{2+}$ biosorption. The yeast cell wall has a complex macromolecular structure with a layered organization, including an amorphous inner and a fibrillar outer layer(29). The inner layer mainly consists of $\beta$-glucans and chitin. The outer layer consists predominantly of mannan polymers, highly glycosylated and linked to proteins (mannoproteins)(30).

Several sources suggest that the chitin amine nitrogen is responsible for heavy metals sequestering at the ppm scale $(17,31,32)$. To further investigate this, we assessed the $\mathrm{Pb}^{2+}$ uptake capacity of chitin from shrimp shells, which is similar to that found in the yeast cell wall. We used 20 times more chitin, i.e., $1.8 \mathrm{mg}$, than the maximum equivalent amount present in the $5 \mathrm{mg}$ of yeast, considering a $30 \%$ dry weight of yeast cell wall and a $6 \%$ contribution of chitin per mass to it(30). We added this amount to an aqueous solution of $0.2 \mathrm{~L}$ with $C_{0} 1,000 \mathrm{ppb} \mathrm{Pb}^{2+}$ for $24 \mathrm{~h}$ at $200 \mathrm{rpm}$ and $25^{\circ} \mathrm{C}$. We ran the same experiments with $5 \mathrm{mg}$ of yeast biomass and with 5 $\mathrm{mg}$ of chitin. It was shown that chitin's $\mathrm{Pb}^{2+}$ uptake is negligible, as $C_{0}$ was reduced by less than $0.3 \%$ when we added the $1.8 \mathrm{mg}$ of chitin, which is within the measurement error. Even when the chitin amount added was equal to the total yeast mass $(5 \mathrm{mg}), C_{0}$ was only reduced by $3 \%$, compared to the $\sim 30 \%$ reduction achieved by the yeast biomass (Fig. 5A). Hence, it can be concluded that chitin alone is not contributing to the $\mathrm{Pb}^{2+}$ biosorption process.

Yeast biomass nanomechanical characterization. We employed nanomechanical characterization to investigate biosorption. We assessed the stiffness of the yeast cells before and after $\mathrm{Pb}^{2+}$ exposure. Single-cell mechanical testing by atomic force microscopy (AFM) showed a significant increase in the stiffness of samples following $\mathrm{Pb}^{2+}$ uptake (Fig. 5B). However, when yeast biomass is treated with solutions containing higher $\mathrm{Pb}^{2+}$ levels, mechanical stiffness is not noticeably increased $\left(C_{0} 500\right.$ vs $1,000 \mathrm{ppb} \mathrm{Pb}^{2+}$ ). This cannot be attributed to a potential saturation of the yeast cell wall binding sites, as $\mathrm{Pb}^{2+}$ uptake increases significantly with the increase of $C_{0}$ from 500 to $1,000 \mathrm{ppb} \mathrm{Pb}^{2+}$ (Fig. 2E). While the exact mechanism for this stiffness change is yet to be determined, it is possible that adsorption of even a thin layer of $\mathrm{Pb}^{2+}$, as evidenced by the TEM data (Fig. 3D), can act as a film on the cell surface that fuses the fibrillar structures together, which then effectively resists deformation more than the untreated cell wall. 
A

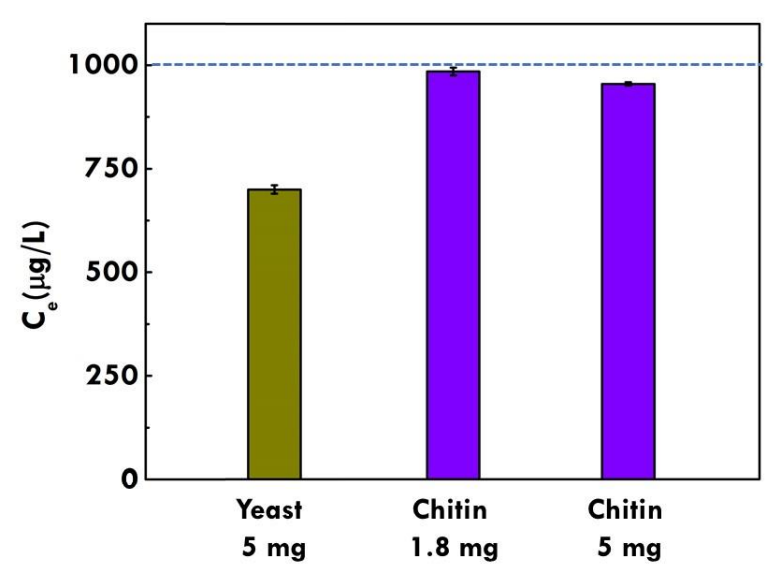

B

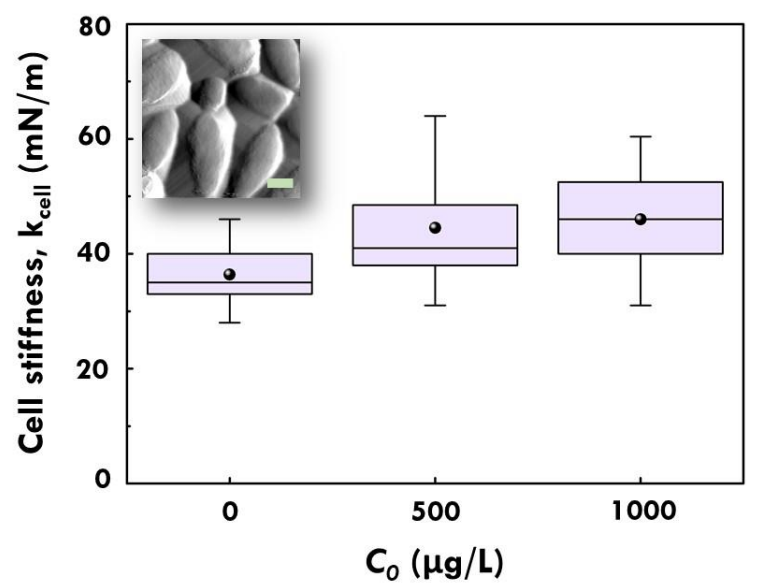

Fig. 5: Chitin's contribution to $\mathrm{Pb}^{2+}$ adsorption and nanomechanical characterization of yeast biomass. (A) $\mathrm{Pb}^{2+} C_{e}$ after biosorption experiments with $5 \mathrm{mg}$ of yeast biomass (green bar), $1.8 \mathrm{mg}$, and $5 \mathrm{mg}$ of chitin (purple bars); blue dotted line represents $C_{0}: 1,000 \mathrm{ppb} \mathrm{Pb}^{2+}$. (B) AFM analysis of yeast cell stiffness. Box-and-whisker plots of the cellular spring constant $\left(\mathrm{k}_{\text {cell }}\right)$ calculated from force-extension curves acquired from yeast cells incubated with $C_{0}$ of 0,500 , and 1,000 $\mathrm{ppb} \mathrm{Pb}^{2+}$. Boxed region indicates upper and lower quartiles for each data set; median is indicated by the horizontal line within the box; mean is indicated by the bullet point; whiskers extend to high and low data points ( $\mathrm{n}>70$ force measurements from $\geq 8$ cells per condition). AFM deflection retrace image of yeast cells is shown in the inset (scale bar: $2 \mu \mathrm{m}$ ).

\section{Discussion}

This work reports the biosorption isotherm and kinetics of initial $\mathrm{Pb}^{2+}$ concentration at the $\mathrm{ppb}$ scale, using lyophilized $S$. cerevisiae yeast cells as biosorbents. Comparing our results with prior studies of similar systems at the ppm scale it can be concluded that the biosorption processes at the ppb scale happen faster; the fastest equilibrium attainment reported at the ppm scale is 10 $\min (18)$, while our results show that equilibrium is achieved in the first 5 minutes of contact. The adsorption isotherm reported in our study (Fig. 2E) follows the same pattern as the adsorption isotherms reported in the ppm literature (e.g., fig. S1). Interestingly, the maximum $\mathrm{Pb}^{2+}$ uptake capacity of $12 \mathrm{mg} / \mathrm{g}$ reported in this study is in the same range as the uptake capacities reported in the ppm literature for untreated inactive $S$. cerevisiae yeast, i.e., $2-30 \mathrm{mg} / \mathrm{g}$ (e.g., table S3), proving the suitability of this biomaterial as a biosorbent at the ppb scale. $\mathrm{pH}$ is a significant factor in the biosorption process in both scales. The rapid biosorption and high $\mathrm{Pb}^{2+}$ uptake are advantageous for the large-scale application of this inexpensive and abundant biomaterial suitable for the removal of trace heavy metals from water.

From the performed analyses, it can be concluded that the cell wall of $S$. cerevisiae contributes significantly to $\mathrm{Pb}^{2+}$ biosorption, and in particular its carboxylic acid and amide groups. By excluding chitin as a biosorbent, mannoproteins and $\beta$-glucans are the potential key $S$. cerevisiae cell wall components, which should be further analyzed to elucidate the biosorption mechanisms involved. The combined outcomes of the TEM, the spectroscopic analyses, and the cellular nanomechanical characterization, validate the likelihood of $\mathrm{N}$-linked $\sigma$-hole attraction to $\mathrm{Pb}^{2+}$ species as a possible mechanism of biosorptive $\mathrm{Pb}$ retention by the mannoprotein/ $\beta$-glucan cell 
wall fraction $(33,34)$, leading to supramolecular assemblies that make yeast cells stiffer after biosorption. These findings open new experimental pathways for approaching the challenging task of biosorption investigation at the ppb scale.

The results showed herein, together with the fact that 3 million tons of yeast are used annually by the global fermentation industry(35) and that the yeast market is expected to grow by $35 \%$ in the next 5 years(36), indicate that exploiting this biosorbent is practically feasible and economically attractive. In addition, due to its simplicity, this approach can be easily reproduced, locally sourced, and applied at scale. The approach described here compares favorably to many of the highly sophisticated synthetic biology and advanced nanomaterials approaches that have also been examined as candidates for heavy metal removal from water(37, 38). Applying such a lowvalue resource to remove trace contaminants from water could lead to significant environmental benefits for the water and wastewater treatment utilities, including their decarbonization due to limited energy use, and waste reduction as yeast cells are biodegradable. Moreover, potential desorption processes would allow for heavy metals reclamation, enhancing the application of circular economic models.

\section{References and Notes}

1. Q. Zhou, N. Yang, Y. Li, B. Ren, X. Ding, H. Bian, X. Yao, Total concentrations and sources of heavy metal pollution in global river and lake water bodies from 1972 to 2017. Global Ecology and Conservation. 22, e00925 (2020).

2. R. Klein, J. S. Tischler, M. Mühling, M. Schlömann, in Geobiotechnology I, A. Schippers, F. Glombitza, W. Sand, Eds. (Springer Berlin Heidelberg, Berlin, Heidelberg, 2013; http://link.springer.com/10.1007/10_2013_265), vol. 141 of Advances in Biochemical Engineering/Biotechnology, pp. 109-172.

3. B. S. Acharya, G. Kharel, Acid mine drainage from coal mining in the United States - An overview. Journal of Hydrology. 588, 125061 (2020).

4. Statista, Number of active mines in the United States from 2000 to 2019 (2021), (available at https://www.statista.com/statistics/949127/number-active-mines-united-states-bycommodity/).

5. Abandonedmines.gov, Water Pollution, (available at https://www.abandonedmines.gov/water-pollution).

6. World Economic Forum, “A New Circular Vision for Electronics: Time for a Global Reboot" (United Nations, Geneva, Switzerland, 2019), p. 24.

7. Statista, World production of lead from 2006 to 2020 (2021), (available at https://www.statista.com/statistics/264872/world-production-of-lead-metal/).

8. J. S. Casas, J. Sordo, Lead: Chemistry, Analytical Aspects, Environmental Impact and Health Effects (Elsevier, The Netherlands, 2006). 
9. R. J. Santucci, J. R. Scully, The pervasive threat of lead $(\mathrm{Pb})$ in drinking water: Unmasking and pursuing scientific factors that govern lead release. Proc Natl Acad Sci USA. 117, 23211-23218 (2020).

10. P. R. Sharma, A. Chattopadhyay, C. Zhan, S. K. Sharma, L. Geng, B. S. Hsiao, Lead removal from water using carboxycellulose nanofibers prepared by nitro-oxidation method. Cellulose. 25, 1961-1973 (2018).

11. WHO, "Lead in Drinking-water. Background document for development of WHO Guidelines for Drinking-water Quality" (WHO/SDE/WSH/03.04/09/Rev/1, WHO, 2011), (available at https://www.who.int/water_sanitation_health/dwq/chemicals/lead.pdf).

12. Aquatech, Lead levels to be halved under revised Drinking Water Directive (2018), (available at https://www.aquatechtrade.com/news/water-treatment/lead-levels-to-be-halvedunder-revised-drinking-water-directive/).

13. NSF International, Revisions to drinking water standard tighten lead leaching allowance for plumbing products (2020), (available at https://phys.org/news/2020-09-standard-tightenleaching-plumbingproducts.html?utm_source=nwletter\&utm_medium=email\&utm_campaign=daily-nwletter).

14. D. B. Johnson, K. B. Hallberg, Acid mine drainage remediation options: a review. Science of The Total Environment. 338, 3-14 (2005).

15. G. L. Sun, Erin. E. Reynolds, A. M. Belcher, Using yeast to sustainably remediate and extract heavy metals from waste waters. Nat Sustain. 3, 303-311 (2020).

16. H. Tian, M. A. Alkhadra, K. M. Conforti, M. Z. Bazant, ACS EST Water, in press, doi:10.1021/acsestwater.1c00234.

17. M. Tsezos, in Geobiotechnology I: Metal-related Issues, A. Schippers, F. Glombitza, W. Sand, Eds. (Springer-Verlag, Berlin, Heidelberg, 2014), pp. 173-209.

18. Y. Ojima, S. Kosako, M. Kihara, N. Miyoshi, K. Igarashi, M. Azuma, Recovering metals from aqueous solutions by biosorption onto phosphorylated dry baker's yeast. Sci Rep. 9, 225 (2019).

19. J. Wang, C. Chen, Biosorption of heavy metals by Saccharomyces cerevisiae: A review. Biotechnology Advances. 24, 427-451 (2006).

20. C. F. Baes, R. E. Mesmer, The hydrolysis of cations (Wiley, New York, 1976).

21. Eawag, ChemEQL - a software for the calculation of chemical equilibria (2021), (available at https://www.eawag.ch/en/department/surf/projects/chemeql/).

22. S. Lagergren, About the theory of so-called adsorption of soluble substances. K. Sven. Vetenskapsakad. Handl. 24, 1-39 (1898). 
23. I. Langmuir, THE CONSTITUTION AND FUNDAMENTAL PROPERTIES OF SOLIDS AND LIQUIDS. PART I. SOLIDS. J. Am. Chem. Soc. 38, 2221-2295 (1916).

24. J. Wang, X. Guo, Adsorption isotherm models: Classification, physical meaning, application and solving method. Chemosphere. 258, 127279 (2020).

25. L. E. Hudson, C. D. McDermott, T. P. Stewart, W. H. Hudson, D. Rios, M. B. Fasken, A. H. Corbett, T. J. Lamb, Characterization of the Probiotic Yeast Saccharomyces boulardii in the Healthy Mucosal Immune System. PLoS ONE. 11, e0153351 (2016).

26. Y. Goksungur, Biosorption of cadmium and lead ions by ethanol treated waste baker's yeast biomass. Bioresource Technology. 96, 103-109 (2005).

27. P. B. Dengis, P. G. Rouxhet, Preparation of yeast cells for surface analysis by XPS. Journal of Microbiological Methods. 26, 171-183 (1996).

28. P. B. Dengis, M. J. Genet, P. G. Rouxhet, Microbial Cells by XPS: Analysis of Brewing Yeast Saccharomyces cerevisiae. Surface Science Spectra. 4, 21-27 (1996).

29. M. D. Machado, S. Janssens, H. M. V. M. Soares, E. V. Soares, Removal of heavy metals using a brewer's yeast strain of Saccharomyces cerevisiae : advantages of using dead biomass. Journal of Applied Microbiology. 106, 1792-1804 (2009).

30. P. Orlean, Architecture and Biosynthesis of the Saccharomyces cerevisiae Cell Wall. Genetics. 192, 775-818 (2012).

31. M. Tsezos, S. Mattar, A further insight into the mechanism of biosorption of metals, by examining chitin epr spectra. Talanta. 33, 225-232 (1986).

32. M. Tsezos, B. Volesky, Biosorption of uranium and thorium. Biotechnol. Bioeng. 23, 583604 (1981).

33. G. Mahmoudi, A. Bauzá, M. Amini, E. Molins, J. T. Mague, A. Frontera, On the importance of tetrel bonding interactions in lead( II ) complexes with (iso)nicotinohydrazide based ligands and several anions. Dalton Trans. 45, 10708-10716 (2016).

34. P. Politzer, J. S. Murray, T. Clark, G. Resnati, The $\sigma$-hole revisited. Phys.Chem.Chem.Phys. 19, 32166--32178 (2017).

35. LESAFFRE, The yeast economy. Explore Yeast (2021), (available at https://www.exploreyeast.com/article/the-yeast-economy).

36. Statista, Value of the yeast product market worldwide from 2017 to 2026 (2021), (available at https://www.statista.com/statistics/728147/global-yeast-product-market-size/).

37. J. Yang, B. Hou, J. Wang, B. Tian, J. Bi, N. Wang, X. Li, X. Huang, Nanomaterials for the Removal of Heavy Metals from Wastewater. Nanomaterials. 9, 424 (2019). 
38. C. Wang, A. S. Helal, Z. Wang, J. Zhou, X. Yao, Z. Shi, Y. Ren, J. Lee, J. Chang, B. Fugetsu, J. Li, Uranium In Situ Electrolytic Deposition with a Reusable Functional Graphene-Foam Electrode. Adv. Mater., 2102633 (2021).

39. E. Gibbs, J. Hsu, K. Barth, J. W. Goss, Characterization of the nanomechanical properties of the fission yeast ( Schizosaccharomyces pombe ) cell surface by atomic force microscopy. Yeast. 38, 480-492 (2021).

40. C. B. Volle, M. A. Ferguson, K. E. Aidala, E. M. Spain, M. E. Núñez, Quantitative Changes in the Elasticity and Adhesive Properties of Escherichia coli ZK1056 Prey Cells During Predation by Bdellovibrio bacteriovorus 109J. Langmuir. 24, 8102-8110 (2008).

41. B. C. Smith, Infrared Spectral Interpretation: A Systematic Approach (CRC Press, ed. 1st, 1999).

42. A. De Rossi, M. R. Rigon, M. Zaparoli, R. D. Braido, L. M. Colla, G. L. Dotto, J. S. Piccin, Chromium (VI) biosorption by Saccharomyces cerevisiae subjected to chemical and thermal treatments. Environ Sci Pollut Res. 25, 19179-19186 (2018).

43. A. Dutta, L. Zhou, C. O. Castillo-Araiza, E. De Herdt, Cadmium(II), Lead(II), and Copper(II) Biosorption on Baker's Yeast (Saccharomyces cerevesiae). J. Environ. Eng. 142 (2016), doi:10.1061/(ASCE)EE.1943-7870.0001041.

44. M. T. El-Sayed, Removal of lead(II) by Saccharomyces cerevisiae AUMC 3875. Ann Microbiol. 63, 1459-1470 (2013).

45. D. Limin, D. Juan, B. Xin, Y. Naili, F. Chunhui, Z. Ying, in 2009 International Conference on Environmental Science and Information Application Technology (IEEE, Wuhan, China, 2009; http://ieeexplore.iee.org/document/5200221/), pp. 712-715.

46. K. Parvathi, R. Nagendran, R. Naresh Kumar, Lead biosorption onto waste beer yeast byproduct, a means to decontaminate effluent generated from battery manufacturing industry. Electron. J. Biotechnol. 10, 0-0 (2007).

47. A. Naeem, J. R. Woertz, J. B. Fein, Experimental Measurement of Proton, Cd, Pb, Sr, and Zn Adsorption Onto the Fungal Species Saccharomyces Cerevisiae. Environ. Sci. Technol. 40, 5724-5729 (2006).

Acknowledgments: We thank the MIT Koch Institute's Robert A. Swanson (1969) Biotechnology Center for technical support, and specifically the Nanotechnology Materials Lab for assisting in TEM sample preparation and imaging. We acknowledge the MIT Materials Research Science and Engineering Center (MRSEC) for assisting with TEM imaging and ATRFTIR analyses. We also thank the MIT Center for Environmental Health Sciences (CEHS) and in particular Dr. Bogdan Fedeles for the helpful discussions and troubleshooting concerning the ICP-MS analyses of our samples. We are grateful to Dr. Constantinos Katsimpouras from the MIT Metabolic Engineering Laboratory for assisting with the HPLC analyses. We also thank Lorena Altamirano for her assistance with biological methods and protocols. 


\section{Funding:}

Bodossaki Foundation, Stamatis G. Mantzavinos's Memorial Postdoctoral Scholarship (P.M.S.). Standard Banking Group sponsorship to the MIT CBA (A.M.). This work was also supported by MIT CBA Consortia funding.

\section{Author contributions:}

Conceptualization: P.M.S., C.E.A., M.T., H.G., N.G.

Methodology: P.M.S., C.E.A., M.T., J.G., E.M.D.

Investigation: P.M.S., C.E.A. J.G., C.B.

Visualization: P.M.S., C.E.A.

Funding acquisition: P.M.S., C.E.A., F.T., A.M., N.P.P., B.W.S., N.G.

Project administration: P.M.S., C.E.A.

Supervision: C.E.A., M.T., H.G., N.G.

Writing - original draft: P.M.S., C.E.A.

Writing - review \& editing: All authors

Competing interests: Authors declare that they have no competing interests.

Data and materials availability: All data are available in the main text or the supplementary materials. Additional data supporting the results presented herein can be provided upon request. 